\title{
Reprogramming of Human Huntington Fibroblasts Using mRNA
}

\author{
Antje Arnold, ${ }^{1}$ Yahaira M. Naaldijk, ${ }^{1}$ Claire Fabian, ${ }^{2}$ Henry Wirth, ${ }^{3}$ \\ Hans Binder, ${ }^{3}$ Guido Nikkhah, ${ }^{4}$ Lyle Armstrong, ${ }^{5}$ and Alexandra Stolzing ${ }^{1}$ \\ ${ }^{1}$ Fraunhofer Institute for Cell Therapy and Immunology, Perlickstraße 1, 04103 Leipzig, Germany \\ ${ }^{2}$ Institute of Virology, University of Leipzig, Johannisallee 30, 04103 Leipzig, Germany \\ ${ }^{3}$ Interdisciplinary Centre for Bioinformatics, University of Leipzig, Härtelstraße 16-18, 04107 Leipzig, Germany \\ ${ }^{4}$ Department Stereotactic and Functional Neurosurgery, University Hospital of Freiburg, Breisacher Straße 67, \\ 79106 Freiburg, Germany \\ ${ }^{5}$ Institute of Human Genetics, Newcastle University, Central Parkway, Newcastle upon Tyne NE1 3BZ, UK
}

Correspondence should be addressed to Alexandra Stolzing, alexandra.stolzing@izi.fraunhofer.de

Received 10 August 2011; Accepted 7 September 2011

Academic Editors: A. Kretsovali, L. Shevde, and A. Tavares

Copyright (C) 2012 Antje Arnold et al. This is an open access article distributed under the Creative Commons Attribution License, which permits unrestricted use, distribution, and reproduction in any medium, provided the original work is properly cited.

\begin{abstract}
The derivation of induced pluripotent stem cells (iPS) from human cell sources using transduction based on viral vectors has been reported by several laboratories. Viral vector-induced integration is a potential cause of genetic modification. We have derived iPS cells from human foreskin, adult Huntington fibroblasts, and adult skin fibroblasts of healthy donors using a nonviral and nonintegrating procedure based on mRNA transfer. In vitro transcribed mRNA for 5 factors, oct-4, nanog, klf-4, c-myc, sox-2 as well as for one new factor, hTERT, was used to induce pluripotency. Reprogramming was analyzed by qPCR analysis of pluripotency gene expression, differentiation, gene expression array, and teratoma assays. iPS cells were shown to express pluripotency markers and were able to differentiate towards ecto-, endo-, and mesodermal lineages. This method may represent a safer technology for reprogramming and derivation of iPS cells. Cells produced by this method can more easily be transferred into the clinical setting.
\end{abstract}

\section{Introduction}

The feasibility of reprogramming somatic cells to induced pluripotent stem cells (iPS) [1-4] has led to the possibility of developing disease-specific iPS cells for improved disease modeling in vitro [5-7] and potential use in clinical applications $[8,9]$. Since the initial generation of iPS cells from mouse embryonic fibroblast (MEF) cells [1], there have been numerous refinements of the method. The potential therapeutic application of initial iPS cell lines was hampered by the fact that applied methods of iPS cell derivation modified the host genome through the integration of DNA sequences [3, 10-15]. Kim and colleagues [16] showed that it is possible to reprogram human foreskin fibroblasts through exposure to membrane-permeable recombinant proteins of the pluripotency factors Oct-4, Sox-2, Klf-4, and c-Myc. The factors were fused to a 9-arginine sequence to establish the ability of cell penetration. HEK 293 cells were transfected with plasmids for producing the described proteins. The whole HEK 293 cell extract was used for reprogramming.
The method was refined by Zhou et al. [17] for MEF cells using recombinant cell-penetrating proteins. It has been shown that the modified mRNA-mediated delivery of reprogramming factors based on nucleofection is an efficient and nontoxic alternative approach to cell modification [18] which has recently facilitated the derivation of iPS cell lines [19-21]. Here, we investigate in vitro transcribed mRNA transfection as a method for producing iPS cells that does not bear any risk with respect to genetic modification. In addition, we show the reprogramming of fibroblasts from Huntington disease donors, the use of alternative reprogramming cocktails, alternative factor combinations, and the application of different mRNA-transfection techniques.

\section{Materials and Methods}

2.1. Ethics Statement. The study was approved by the Institutional Review Board of the Universities of Leipzig and Freiburg, Germany. All patients provided written informed 
consent for the collection of samples and subsequent analysis.

2.2. Materials. Unless indicated otherwise, all chemicals were purchased from Sigma-Aldrich, Germany.

2.3. Cells. Normal human adult dermal fibroblasts ( 21 years, female) were obtained from provitro $\mathrm{GmbH}$, Germany. Dermal fibroblasts from Huntington patients (56 years, male and 41 years, female) were kindly donated by the Albert Ludwig University of Freiburg. Foreskin fibroblasts (11 and 4 years, male) were provided by the University of Leipzig. Lysates of human embryonic stem cells (hESCs = Wisconsin $\mathrm{H} 1$ and $\mathrm{H} 9$ [22]) were provided by Lyle Armstrong from the University of Newcastle UK (NB: no living hESCs were imported into Germany). H9 cell extracts were sent in two shipments. PhoenixGP cells were provided by the Stanford University (http://www.stanford.edu/group/nolan/).

2.4. Cell Culture. All cell cultures were grown in DMEM high-glucose medium (Invitrogen), supplemented with 10\% FBS (Hyclone) and $100 \mathrm{IU} / \mathrm{mL}$ penicillin $/ 100 \mu \mathrm{g} / \mathrm{mL}$ streptomycin. All plates and dishes for iPS cell cultures were coated with $0.1 \%$ gelatin (gelatin from porcine skin, type A). mRNA-iPS cells were cultured with an additional $8 \mathrm{ng} / \mathrm{mL}$ bFGF (Invitrogen), 1\% nonessential amino acids (Invitrogen), and $0.1 \mathrm{mM} 2$-mercaptoethanol were passaged mechanically. We used human adult and foreskin fibroblasts from the same donor as mitomycin-C- $(10 \mu \mathrm{g} / \mathrm{mL})$ inactivated feeder cells. MEFs as feeder cells were established from dissociated C57BL/6 mouse embryos (13.5-14 d gestation) and inactivated by mitomycin $\mathrm{C}(10 \mu \mathrm{g} / \mathrm{mL})$. All non-mRNA iPS cells were cultured under normoxia $\left(21 \% \mathrm{O}_{2}\right)$, and mRNAiPS cells were cultured under hypoxic conditions $\left(5 \% \mathrm{O}_{2}\right)$.

2.5. Plasmid Construction. The plasmids pMXs-hNanog (plasmid 18115), pMXs-hSox2 (plasmid 17965), pMXshOct4 (plasmid 17964), pMXs-hKlf4 (plasmid 17219), pBabe-hygro-hTERT (plasmid 1773), and pBabe-c-myc-zeo (plasmid 17758) were purchased from Addgene.org, a US nonprofit organization. pTagRFP-C was bought from Evrogen, Russia. For creating new restriction sites, cloning primers were designed. The sequences are listed in Supplementary Table 1B (See Supplementary Material available online at doi: 10.5402/2012/124878). New plasmids were constructed by direct cloning of the insert into pcDNA3 (Invitrogen). The ligation was performed with T4-DNA ligase, according to the manufacturer's guidelines (Fermentas, Germany).

2.6. In Vitro mRNA Production. The parts of the plasmids containing reprogramming factor or fluorescence sequences (pcDNA3-hNanog, pcDNA3-hOct4, pcDNA3-hSox2, pcDNA3-hKlf4, pcDNA3-hc-Myc, pcDNA3-hTERT, and pcDNA3-RFP-C) were amplified by PCR with SP6 and T7 primers (see Supplementary Figure S1C). The PCR products for hNanog, hOct4, hSox2, hKlf4, hc-Myc, hTERT, and RFP were purified using the PCR purification kit NucleoSpin Extract II Kit (Macherey-Nagel). The purified PCR product was employed for an in vitro transcription reaction using the
“T7 mScript Standard mRNA Production System” (Epicentre Biotechnologies). The mRNA concentration was measured using a "NanoDrop" photometer (Peqlab) and the quality of mRNA was measured with an "Agilent 2100 Bioanalyzer" (Agilent Technology).

2.7. Transfection. The human fibroblasts were transfected with $3 \mu \mathrm{g}$ of mRNA by nucleofection (NHDF-VPD-1001, Lonza). Four hours after transfection, the normal fibroblast medium was changed to mRNA-iPS medium as described above. At $72 \mathrm{~h}, 144 \mathrm{~h}$, and $216 \mathrm{~h}$ after initial nucleofection, the adherent cells were transfected with "FuGENE HD" (Roche) according to the manufacturer's instructions and replaced with culture medium at $4 \mathrm{~h}$ after each transfection. The ratio of "FuGENE HD" reagent and mRNA was $8 \mu \mathrm{L}$ per $3 \mu \mathrm{g}$ of mRNA. Transfection efficiency was controlled using RFP-mRNA. Cells derived from these transfections were cultured in the same way as iPS cells obtained by other methods described elsewhere.

2.8. Immunocytochemistry. Cells were fixed with $4 \%$ paraformaldehyde, washed and permeabilized with $0.5 \%$ Triton $\mathrm{X}-100$ in $1 \mathrm{x}$ PBS. Nuclei were stained with $4^{\prime}, 6$-diamidino-2phenylindole dilactate. Cells were blocked with $10 \%$ donkey serum and incubated for $1 \mathrm{~h}$ at $37^{\circ} \mathrm{C}$ with primary antibodies in $1 x$ PBS with $1 \%$ donkey serum. After washing 3 times, cells were incubated with fluorescence-labeled secondary antibodies (Cy2 and Cy3 1:750; Jackson ImmunoResearch Laboratory) at $37^{\circ} \mathrm{C}$ for $1 \mathrm{~h}$. Staining analysis was performed with a fluorescence microscope (Axio Observer, Zeiss). The following antibodies were used: Tra-1-60 (1:50; R\&D), SSEA3 ( $1: 100 ; R \& D)$, SSEA4 ( $1: 150 ; R \& D)$, Nanog ( $1: 1000 ;$ Abcam), Oct4 (1:250; Abcam), Sox2 (1:50; Santa Cruz), AFP ( $1: 75 ; \mathrm{R} \& D)$, aggrecan ( $1: 50$; Acris), collagenII $(1: 20$; Serotec $)$, cytokeratin $18(1: 100 ;$ Abcam $)$, cytokeratin 14 (1: 150; Epitomics), B1-Integrin (1:50; Pierce Endogen), GFAP (1:350, Chemicon), and tubulin BIII-FITC ( $1: 30$; Serotec).

2.9. Staining for Alkaline Phosphatase, Collagen, and Adipogenesis. Detached iPS cell colonies were washed in 1x PBS and fixed in $70 \%$ ethanol, followed by incubation for $30 \mathrm{~min}$ in alkaline phosphatase buffer ( $0.2 \mathrm{M}$ Tris, $\mathrm{pH} 8.5$, dimethylformamide, naphthol phosphate, ASBI $50 \mu \mathrm{g} / \mathrm{mL}, 1 \mathrm{mg} / \mathrm{mL}$ Fast Red), washing in $1 \mathrm{x}$ PBS and photographing.

iPS-derived and control cells were incubated in differentiation medium, fixed with $70 \%$ ethanol, washed with water and stained with Alizarin Red for $30 \mathrm{~min}$ at room temperature (RT) to detect collagen, washed and photographed.

Cells differentiated in adipocyte lineage were fixed with $4 \%$ paraformaldehyde for $40 \mathrm{~min}$ at RT, washed and stained with Oil Red O solution for $50 \mathrm{~min}$ at RT, washed and photographed.

2.10. RNA Extraction and PCR. Total RNA was extracted using Trifast reagent according to the manufacturer's instructions (Peqlab). One $\mu \mathrm{g}$ of total RNA was treated with DNaseI (Invitrogen) to eliminate possible genomic DNA (gDNA) contamination. This procedure was followed by cDNA synthesis using a reverse transcriptase "SuperscriptIII" 
(Invitrogen) and Oligo $(\mathrm{dT})_{18}$-Primers (Fermentas). cDNA was diluted 1:10 and $2 \mu \mathrm{L}$ were added to "Express SYBR GreenER qPCR Supermix Universal” (Invitrogen) for qPCR (performed on a LightCycler 480, Roche). Primer sequences are indicated in supplementary Table 1A. Relative quantification was calculated with $2^{-\Delta \Delta C t}$ and normalized to hGAPDH. Data were presented as levels related to the expression level in the hESCs (H9), with the hES cell expression profiles set as a value of 1 .

2.11. Bisulfite Genomic Sequencing. gDNA was isolated using Trifast reagent (Peglab). $500 \mathrm{ng}$ of gDNA were used for the "MethylCode Bisulfite Conversation Assay" (Invitrogen). The promoter regions of Oct 4 and Nanog were amplified by PCR using primer sets previously described [23]. The PCR products were cloned into pCRII-TOPO-TA plasmid and sequenced (IZKF, University of Leipzig).

2.12. In Vitro Differentiation of mRNA-iPS Cells. mRNAiPS medium was replaced with the following differentiation media: chondrocyte medium: DMEM low glucose, $100 \mathrm{IU} / \mathrm{mL}$ penicillin $/ 100 \mu \mathrm{g} / \mathrm{mL}$ streptomycin, $1 \%$ insulintransferrin-selenium supplement, $10^{-7} \mathrm{M}$ dexamethasone, $150 \mu \mathrm{M}$ ascorbic-2-phosphate, $20 \mu \mathrm{M}$ linolic acid, $0.1 \mathrm{ng} / \mathrm{mL}$ TGF- $\beta$ (Oncogene Sciences); hepatic medium I: DMEM low glucose, $10 \%$ FBS, $100 \mathrm{IU} / \mathrm{mL}$ penicillin $/ 100 \mu \mathrm{g} / \mathrm{mL}$ streptomycin, $20 \mathrm{ng} / \mathrm{mL}$ EGF, $10 \mathrm{ng} / \mathrm{mL}$ HGF, $8 \mathrm{ng} / \mathrm{mL}$ bFGF, and $0.61 \mathrm{~g} / \mathrm{L}$ nicotinamide. After 7 days, hepatic medium I was replaced with hepatic medium II: DMEM low glucose, $10 \%$ FBS, $100 \mathrm{IU} / \mathrm{mL}$ penicillin $/ 100 \mu \mathrm{g} / \mathrm{mL}$ streptomycin, $10 \mathrm{ng} / \mathrm{mL}$ oncostatin $\mathrm{M}, 10^{-8} \mathrm{M}$ dexamethasone, $1 \%$ insulin-transferrin-selenium supplement; adipocyte medium: DMEM low glucose, 10\% FBS, $100 \mathrm{IU} / \mathrm{mL}$ penicillin/ $100 \mu \mathrm{g} / \mathrm{mL}$ streptomycin, $1 \%$ insulin-transferrin-selenium supplement, $10^{-8} \mathrm{M}$ dexamethasone, $0.5 \mathrm{mM}$ isobutylmethylxanthine, $100 \mu \mathrm{M}$ indomethacin; neural differentiation medium: DMEM/HAM's F-12, 10\% FBS, $100 \mathrm{IU} / \mathrm{mL}$ penicillin/ $100 \mu \mathrm{g} / \mathrm{mL}$ streptomycin, $1 \%$ insulin-transferrin-selenium supplement, $10^{-7} \mathrm{M}$ retinoic acid, $8 \mathrm{ng} / \mathrm{mL}$ bFGF; keratinocyte medium: DMEM/HAM's F-12, 10\% FBS, $100 \mathrm{IU} / \mathrm{mL}$ penicillin $/ 100 \mu \mathrm{g} / \mathrm{mL}$ streptomycin, $1 \%$ insulintransferrin-selenium supplement, $1.8 \times 10^{-4} \mathrm{M}$ adenine, $0.5 \mu \mathrm{g} / \mathrm{mL}$ hydrocortisone, $10^{-10} \mathrm{M}$ cholera toxin, $10 \mathrm{ng} / \mathrm{mL}$ EGF. Differentiation media were changed every 3 days for 14 days.

2.13. Embryoid Bodies. mRNA-iPS colonies were dissociated into clusters by $0.05 \%$ Trypsin-EDTA and cultured in ultralow attachment dishes to allow the formation of embryoid bodies (EBs). The medium was changed every 3 days. After 9 days, the EBs were harvested and fixed for immunocytochemistry analysis.

2.14. Karyotyping (GTG Banding and Spectral Karyotyping $S K Y)$. Cells were incubated for $2 \mathrm{~h}$ at $37^{\circ} \mathrm{C}$ with Colcemid $(0.14 \mu \mathrm{g} / \mathrm{mL}$ KaryoMAX, Invitrogen $)$ and then in a hypotonic solution $(0.56 \% \mathrm{KCl})$, fixed in methanol/acetic acid $(3: 1)$ and spread onto glass slides for analysis. Metaphases were Gbanded and karyotyped using the software Ikaros (MetaSystems).
2.15. Transduction. For viral vector-directed iPS derivation, cells were seeded $24 \mathrm{~h}$ prior to transfection at a density of $1.5 \times 10^{4}$ cells per $\mathrm{cm}^{2}$. Cotransfection was performed with $0.75 \mu \mathrm{L}$ "Lipofectamine 2000" (Invitrogen) per $0.5 \mu \mathrm{g}$ plasmid DNA and $1 \mathrm{~cm}^{2}$ growth area. Retroviral particles were pseudotyped using pHIT-G [24], which expresses the vesicular stomatitis virus G (VSV-G) envelope protein, to attain a broad cell tropism [25]. For the production of retroviral particles, the packaging cell line PhoenixGP was used, either with the MLV-based shuttle vector pRVH1-eGFP [26] as GFP control or with shuttle vectors containing iPS cell-inducing factors (pMXs shuttle vectors with nanog, oct4, klf4 and sox2 human [4], pBabe-hygro-hTERT [27], and pBabec-myc-zeo [28] vector). The medium was replaced $6 \mathrm{~h}$ after transfection. The supernatant containing the retroviral particles was collected $48 \mathrm{~h}$ after transfection and filtered through a $0.45 \mu \mathrm{m}$ cellulose acetate filter before it was added to the fibroblasts.

2.16. Gene Expression Profiling. Microarray measurements were conducted at the microarray core facility of the Interdisciplinary Centre for Clinical Research (IZKF) Leipzig (University of Leipzig). One $\mu \mathrm{g}$ of total RNA was depleted of ribosomal RNA using the "RiboMinus Kit" (Invitrogen, USA). The cDNA for array hybridization was prepared from depleted RNA using the "WT cDNA Synthesis and Amplification Kit" according to the manufacturer's instructions (Affymetrix, USA). After fragmentation, cDNA was labeled with the "WT Terminal Labeling Kit" (Affymetrix). Aliquots were hybridized to Human Genome 1.0 ST Arrays. Washing and staining steps were performed with an Affymetrix Fluidics Station FS400. All arrays were scanned with a thirdgeneration Affymetrix "GeneChipScanner 3000" equipped with the "7 G" upgrade.

2.17. Microarray Analysis. Raw intensity data of the GeneChip arrays studied were calibrated and transformed into logged expression values (basis 10) using the hook method [29] and subsequently quantile-normalized [30]. For differential expression (DE) analysis, we applied the weighted average difference method (WAD) [31], a fold-change-(FC-) based algorithm for ranking DE genes, in combination with local-pooled error estimates for evaluating the significance of each gene's DE, which has been shown to effectively identify significant DE patterns with a small number of replicated arrays [32]. Lists of DE genes were determined with a false discovery rate of FDR $\leq 0.25$ using the subset-approach for null sampling [33]. In addition to determining DE genes in two-class comparisons (A-versus-B; e.g., fibroblasts-versusiPS), we performed conditional three-class comparisons (Aversus-B-versus-C; e.g., fibroblasts-versus-iPS-versus-ESC) to select genes that are differentially expressed between $\mathrm{A}$ and $\mathrm{B}$ but similarly expressed in $\mathrm{B}$ and $\mathrm{C}$ and vice versa, by appropriately combining the respective two-class WAD scores. Independent component analysis (ICA) and hierarchical clustering were performed with different groups of genes to explore similarity relations between the samples. The results are represented as two-component ICA plots and heat maps, respectively. Gene set enrichment analysis was 


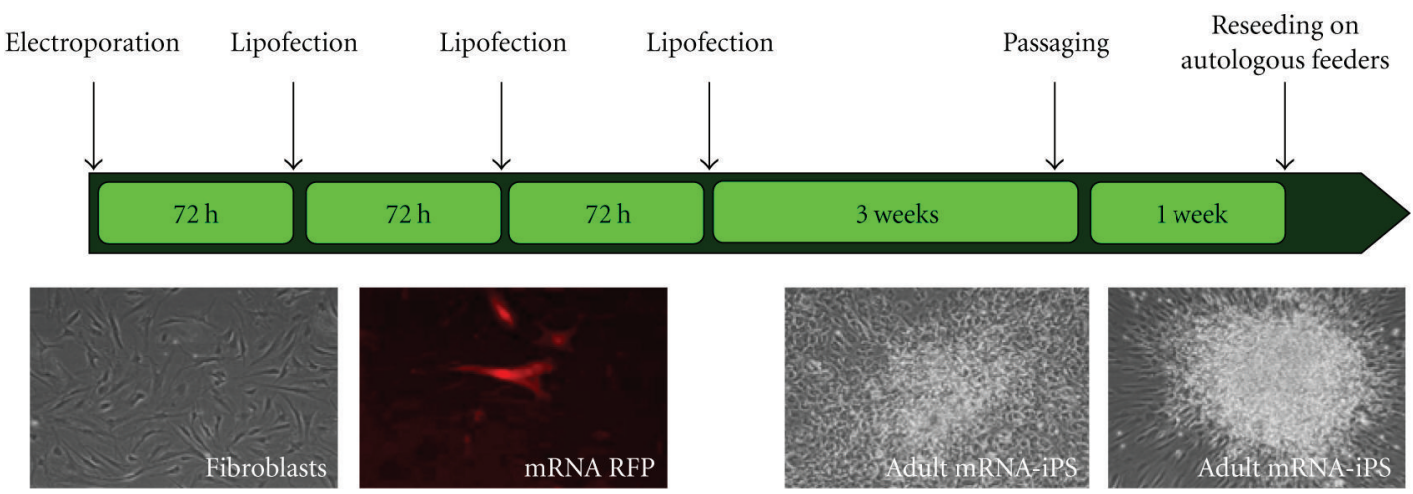

(a) Schematic representation of transfection and cultivation procedure

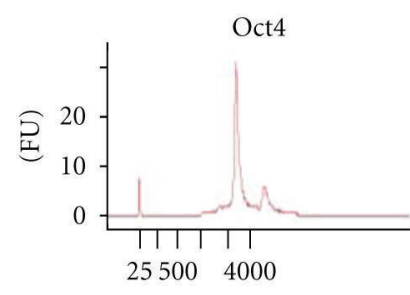

(nt)

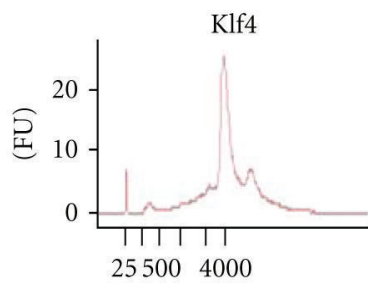

(nt)

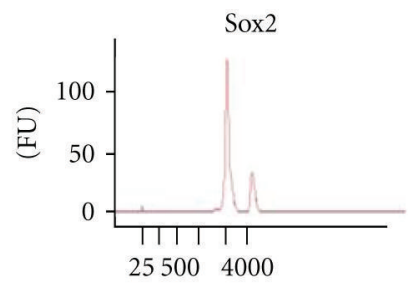

(nt)

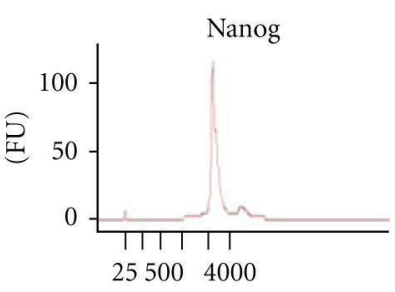

(nt)

(b) mRNA after in vitro transcription

FIgURE 1: Generation of iPS cells using mRNA. (a) Schematic representation of the method: an initial nucleofection is followed by three lipofections at $72 \mathrm{~h}$ intervals and a "resting" period of 3 weeks, after which colony formation is observed. Fluorescence protein (RFP) demonstrates transfection efficacy in the early stages, colony formation at later stages is shown. (b) Examples of the mRNA quality measurement with an Agilent bioanalyzer. The single peaks indicate that only one type of RNA is produced.

conducted using the gene set averaging approach to judge the relevance of groups of genes belonging to a certain biological context [34]. This method estimates the probability that the genes in a pre-defined gene set show the same pattern of association with a phenotype as compared to the rest of the considered genes. Functional gene sets were taken from the GSEA website (http://www.broadinstitute.org/gsea/).

2.18. Teratoma Formation. NOD/LtSz-SCID/SCID mice were maintained under pathogen-free conditions in the animal facility of the University Leipzig. $1 \times 10^{6}$ iPS cells were intramuscularly injected together with Matrigel (BD Biosciences). After 8 weeks, mice were euthanized and the appropriate regions were dissected, fixed in $4 \%$ paraformaldehyde and embedded in paraffin, sliced into $14 \mu \mathrm{m}$ sections and stained with hematoxylin/eosin.

\section{Results}

3.1. Transfection. Human dermal Huntington fibroblasts were transfected with different factor combinations including oct $4+\operatorname{sox} 2+$ klf4 (OSK), oct $4+$ nanog $+\operatorname{sox} 2(\mathrm{ONS})$, and oct $4+$ nanog + hTERT $(\mathrm{ONT})$, oct $4+\operatorname{nanog}+\mathrm{c}-$ myc $(\mathrm{ONM})$, oct $4+$ nanog + klf4 $(\mathrm{ONK})$, oct $4+$ nanog + sox $2+$ hTERT + klf4 + c-myc (ONSTKM). All factors in different combinations were transfected in a ratio of $1: 1$. The foreskin fibroblasts were transfected with OSK exclusively. Transfection efficiency control was performed using the mRNA-RFP (Figure 1(a)). Cells derived from these transfections were cultured in the same way as iPS cells, but no iPS colonies were found in these dishes. For reprogramming using mRNA, the number of transfections is the key issue. We experimented with different approaches: the optimal protocol included an initial electroporation step, followed by 3 lipofections every 72 hours (optimization data not shown). mRNA transfection by electroporation shows the highest transfection efficiency, but results in a high cell toxicity with a lot of cells dying after the treatment. We transfected $0.4 \times 10^{6}$ fibroblasts via electroporation, plated them in a 6-well plate, and changed medium after 4-6h to iPS medium without 2-mercaptoethanol. After $72 \mathrm{~h}$, the cells were $70-80 \%$ confluent and had the optimal cell number for the following lipofection procedures. The process took approximately 3 weeks until colony formations could be observed (Figure 1(a)). After passaging, the cells were grown in clusters and after an additional week the clusters were mechanically isolated and again plated onto dishes coated with donor-derived feeder layers (Figure 1 and Figure S1A). The mRNA-iPS colonies grown on donorderived feeder cells showed less spontaneous differentiation as compared to the mRNA-iPS colonies grown on MEF feeder layers (data not shown). MEF feeder layers were, therefore, no longer used. The resulting cells exhibited colony appearance as well as a high nuclear to cytoplasm ratio with prominent nucleoli and were found to be positive for alkaline phosphatase (Figure 2(a) and Figure S1A), which is typical for pluripotent cells.

iPS colonies derived from foreskin, adult and Huntington disease dermal cells as well as the virus-derived iPS cells 

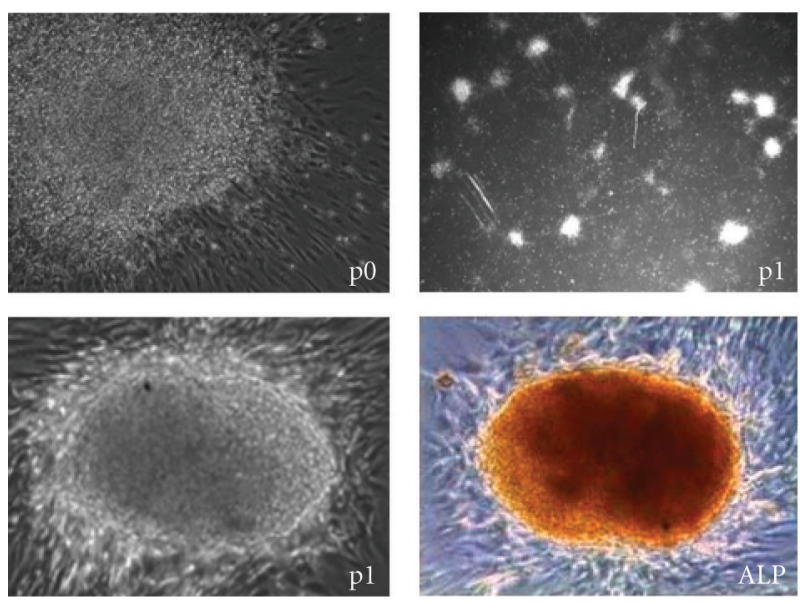

(a) Morphology—adult mRNA-iPS

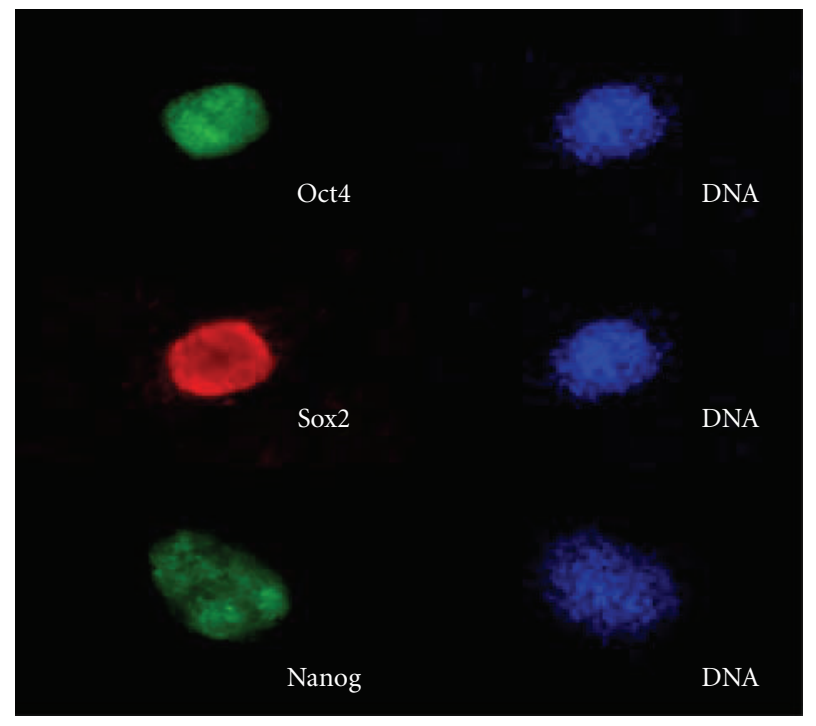

(c) Adult mRNA-iPS cells-Pluripotency

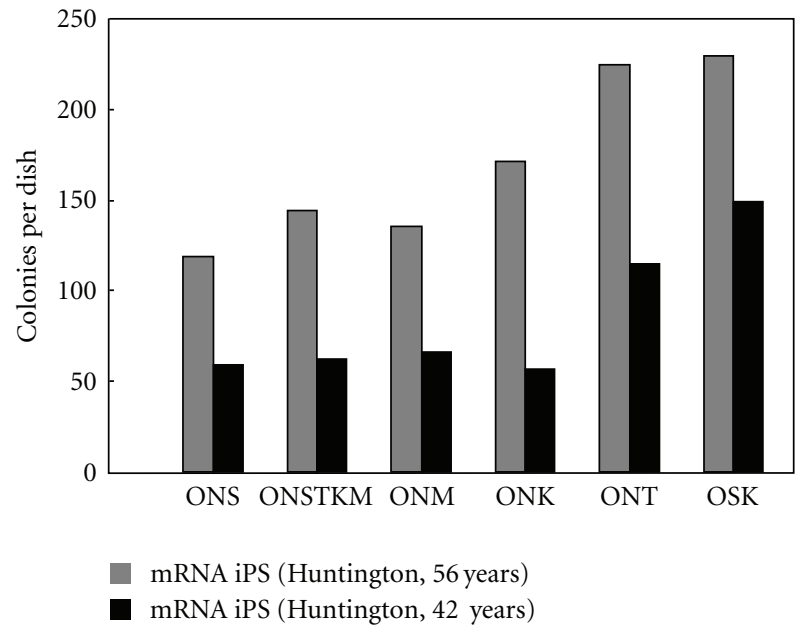

(b) Colony efficiency-Huntington mRNA-iPS

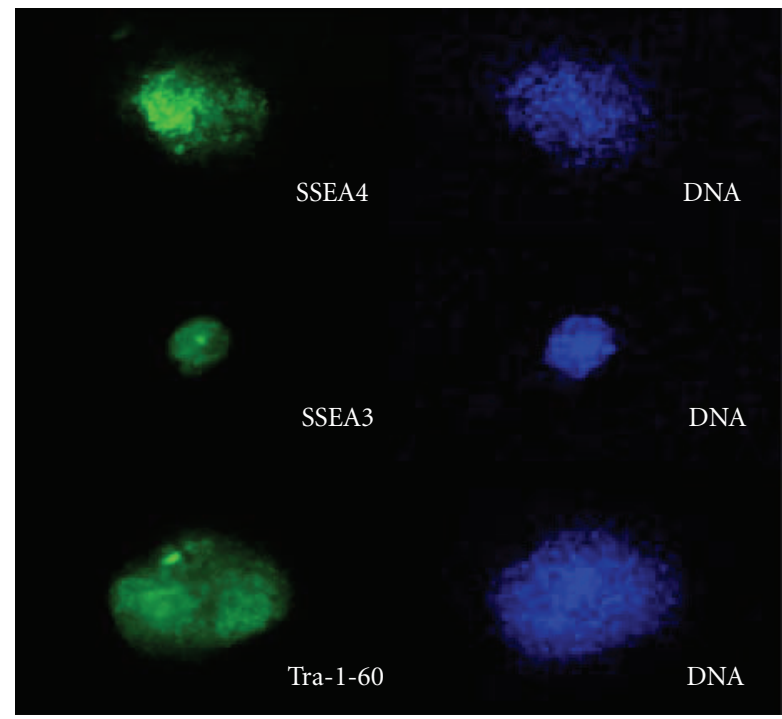

Figure 2: iPS pluripotency of cells derived from adult fibroblasts. (a) Morphology of mRNA-induced iPS cells (passages 0 and 1) and an ALPstained mRNA-iPS colony. (b) Human fibroblasts from two different donors (Huntington patients) were transfected with different factor combinations including oct $4+\operatorname{sox} 2+$ klf4 (OSK), oct $4+\operatorname{nanog}+\operatorname{sox} 2(\mathrm{ONS})$, oct $4+$ nanog + hTERT $(\mathrm{ONT})$, oct $4+$ nanog $+\mathrm{c}-\mathrm{myc}$ $(\mathrm{ONM})$, oct $4+$ nanog + klf4 $(\mathrm{ONK})$, and oct $4+$ nanog + sox $2+$ hTERT + klf4 + c-myc (ONSTKM). Colonies were counted 1 week after derivation ( $\sim$ day 30, cf. Figure 1). (c) Immunofluorescence staining for Oct4, Sox2, Nanog, SSEA4, SSEA3, and Tra-1-60 in mRNA-iPS cells derived from human (female, 21 years) fibroblasts.

were stained for pluripotency proteins (Figure 2(c) and Figures $\mathrm{S} 1 \mathrm{~B}$ and $\mathrm{S} 3 \mathrm{~A}$ ) and were found to be positive for Oct4, Nanog, Sox2, TRA-1-60, SSEA3, and SSEA4, as reported for iPS cells derived by other groups. The original untreated cell populations were negative for these factors (Figure S3B).

The factor combinations of OSK and ONT mRNA seemed to produce the highest colony frequency of all tested factor combinations (about $0.0005 \%$ of input cells). The efficiency of colony formation also seemed to be dependent on the source of the donor fibroblasts (Figure 2(b)). No differences were observed between reprogramming under normoxic $(21 \%)$ or hypoxic (5\%) conditions (data not shown). mRNA-iPS colonies could be expanded over 5 passages at
$5 \%$ oxygen and are still growing. mRNA-iPS cells growing at $21 \%$ oxygen showed a higher rate of spontaneous differentiation, and this protocol was, therefore, abandoned (data not shown).

3.2. qPCR Analysis for Pluripotency. To quantify the expression of pluripotency genes in the mRNA-iPS cells, comparative real-time PCR was conducted with the resulting mRNAiPS cells, hESCs (H9), and the donor fibroblasts. Data are expressed in relation to hESCs (H9). Oct4: mRNA-iPS showed lower expression levels of Oct 4 compared to hESCs, but had higher expression levels compared to the adult donor fibroblasts. The highest Oct4 expression levels in 

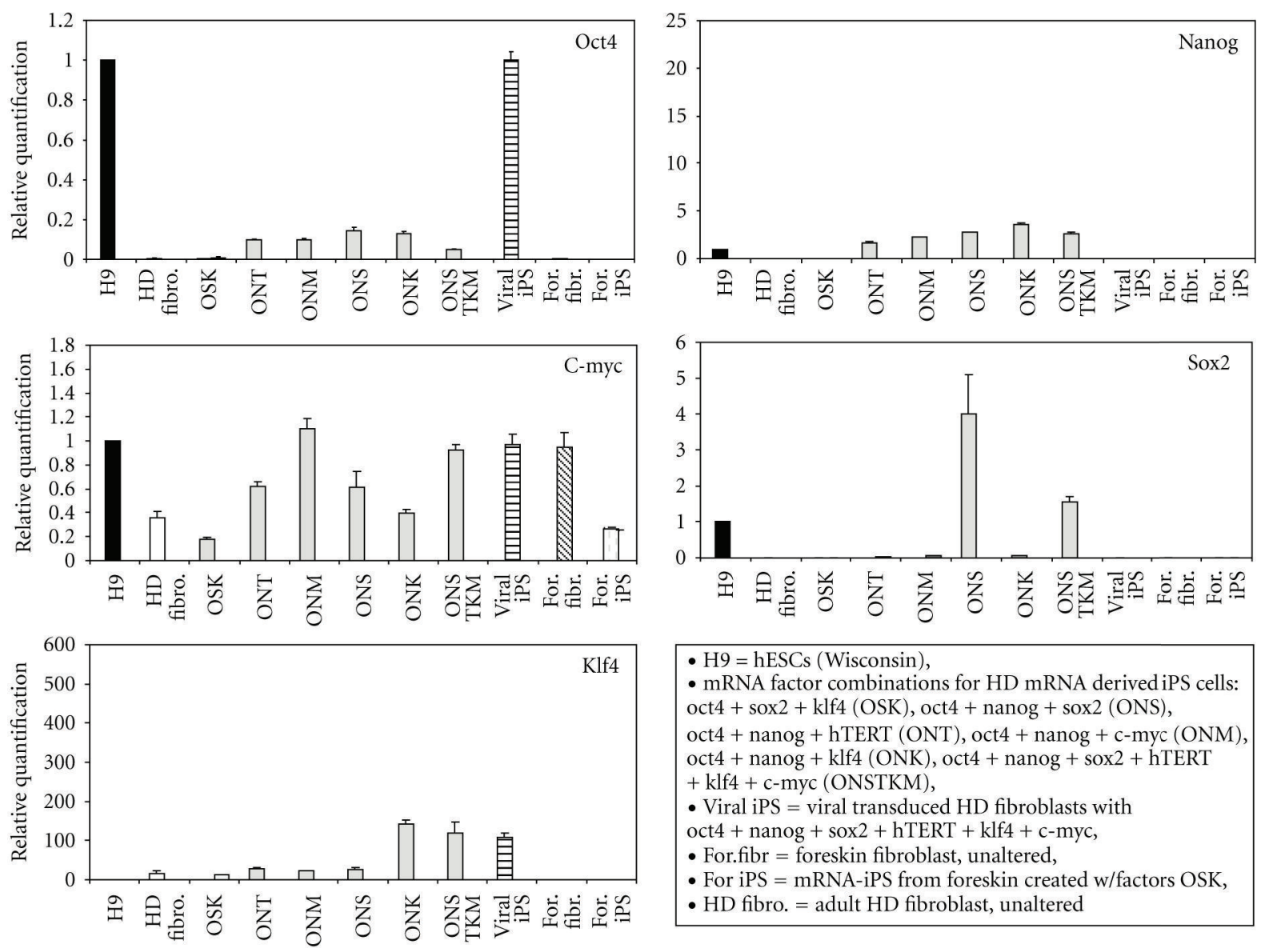

- H9 = hESCs (Wisconsin),

- mRNA factor combinations for HD mRNA derived iPS cells: oct $4+$ sox $2+$ klf4 (OSK), oct $4+$ nanog + sox 2 (ONS),

oct $4+$ nanog + hTERT (ONT), oct $4+$ nanog + c-myc (ONM),

oct $4+$ nanog + klf4 (ONK), oct $4+$ nanog + sox $2+$ hTERT

+ klf4 + c-myc (ONSTKM),

- Viral iPS = viral transduced HD fibroblasts with

oct $4+$ nanog $+\operatorname{sox} 2+$ hTERT + klf4 + c-myc,

- For.fibr $=$ foreskin fibroblast, unaltered,

- For iPS = mRNA-iPS from foreskin created $\mathrm{w} /$ factors OSK,

- HD fibro. $=$ adult HD fibroblast, unaltered

FiguRe 3: qRT-PCR expression analyses of pluripotency markers. qRT-PCR analysis of pluripotency genes Oct4, Sox2, Nanog, Klf4, and c-Myc of mRNA-iPS cells derived from foreskin and Huntington fibroblasts. Controls were H9 and virus-iPS cells.

iPS cells could be detected in colonies derived with ONSmRNA transfection (Figure 3). iPS cells reprogrammed by viral vectors had Oct4 expression levels equal to those found in hESCs (Figure 3).

Remarkably, the virally reprogrammed iPS cells expressed 10-fold more Nanog as compared to fibroblasts (Figure 3). c-Myc expression levels in mRNA-iPS cells were mostly higher than in donor fibroblasts and comparable to those in hESCs. However, the foreskin iPS cells and OSK-iPS cells did not reach the donor fibroblast levels. Sox2 expression could only be detected in mRNA-iPS cells derived with factor combinations containing Sox2 (ONS and ONSTKM) and was higher than in hESCs. Klf4 was upregulated in all iPS cells as compared to fibroblasts. Only OSK-iPS cells and the foreskin iPS cells did not exhibit any up-regulation. Interestingly, the hESCs had equal or lower levels of Klf4 than donor fibroblasts (Figure 3).

3.3. Differentiation. One characteristic of pluripotent stem cells is their capacity to differentiate into all cell types of the body. Spontaneous and directed differentiation assays are well established for the examination of pluripotency. Our adult (Figure 4(a)), Huntington (data not shown), as well as foreskin-derived (Figure S2A) mRNA-iPS cells formed typical embryoid bodies (EBs) in suspension cultures. At day 9, the EBs were stained positive for differentiation markers including aggrecan, collagen II, GFAP, tubulin III, cytokeratin 18, and AFP in mRNA-iPS derived from foreskin (Figure S2B), adult (Figure 4(a)), and Huntington adult fibroblasts (data not shown) as well as in "traditional" viral iPS cells (Figure S3B).

Directed differentiation was performed with undissociated mRNA-iPS colonies derived from foreskin fibroblasts (data not shown) and with monolayers from healthy adult, foreskin, and viral iPS cells (Figure 4(b) and Figures S2A and $\mathrm{S} 3 \mathrm{~B})$. Analytic staining was positive for ectodermal (neuronal, keratinocytic), mesodermal (chondrogenic, osteoblastic, adipocytic), and endodermal (hepatogenic) lineage markers in mRNA-iPS cells as well as in viral iPS controls.

3.4. Gene Expression. Gene expression analysis was performed using Affymetrix whole genome expression arrays to characterize the transcriptional activity of the iPS cells. We compared foreskin and foreskin-derived mRNA-iPS (factors: OSK) cells, adult fibroblasts and their derived mRNA-iPS (factors: ONSKMT), and viral iPS (factors: ONSKMT) cells and two biological replicates of $\mathrm{H} 9$ as reference hESCs (Figures 6 and 7). 

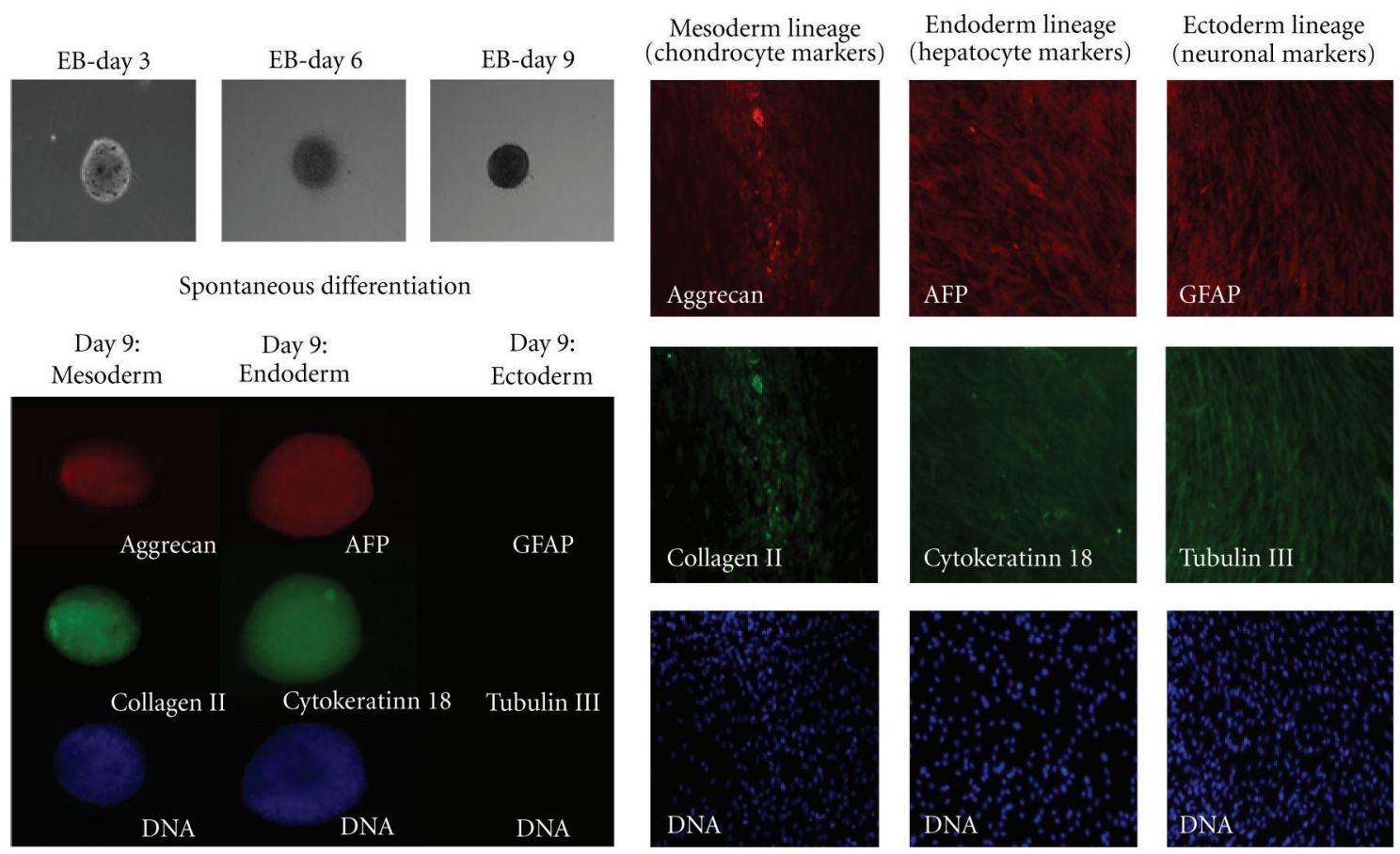

(a) Adult mRNA-iPS cells: Spontaneous differentiation
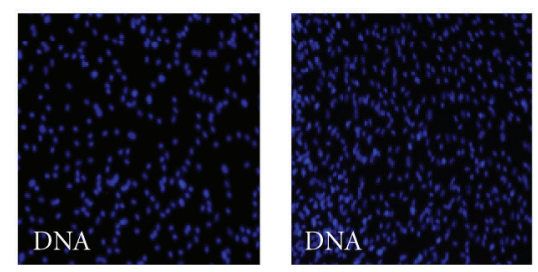

(b) Directed differentiation

FIGURE 4: In vitro differentiation of iPS cells. (a) Spontaneous differentiation into embryoid bodies (EBs) was followed for several days and EBs stained positive for various differentiation markers. (b) mRNA-iPS cells derived from human fibroblasts (female, 21 yrs) were differentiated towards hepatocytes, neurons, and chondrocytes (see Experimental Procedures). Cells expressed lineage-typical markers, (hepatocytes: AFP and cytokeratin 18; neurons: GFAP and tubulin III; chondrocytes: collagen II and aggrecan) and showed morphological changes. All cells were also stained with DAPI, and images were merged with lineage markers.

We performed pair comparisons of fibroblasts-versusmRNA-iPS cells and hESCs-versus-mRNA-iPS cells. The differential expression of mRNA-iPS cells with respect to the reference hESCs (H9) is more pronounced than with respect to the donor fibroblasts. Hierarchical clustering and ICA (Independent Component Analysis) of the expression of 2,665 selected genes revealed a predominant similarity among the hESC samples on the one hand and among the fibroblasts and mRNA-iPS cells on the other hand (Figure 6).

In the next step, we searched for "stemness" genes similarly expressed in hESCs and mRNA-iPS cells and differentially expressed between donor fibroblasts and their derived mRNA-iPS cells. A three-class differential analysis provides a set of 530 genes for the adult cells and 250 genes for the foreskin cells, with a perfect overlap of the latter list (Figure 7(a)). The hierarchical clustering heat map and the ICA plot of these genes illustrate their mutual relation in the samples studied (Figures 7(c) and 7(d)). A three-class comparison of genes, differentially expressed between hESCs and iPS cells and similarly expressed in fibroblasts and mRNAiPS cells provides a group of 380 genes for the adult cells and of 75 genes for the foreskin cells, with a considerable overlap (Figure 6(b)). A gene set analysis of genes up-regulated in undifferentiated hESCs taken from Bhattacharya and colleagues [35] was performed using the max-mean statistics [36]. It is designed to detect unusually large expression changes in either or both directions. The studied set is strongly up-regulated in mRNA-iPS cells as compared to their donor fibroblasts $(P<0.03)$. This result is confirmed by the fact that key pluripotency marker genes studied are strongly increased upon reprogramming, as evidenced both by microarray analysis and qPCR (Figure S5A). The differential expression of these pluripotency markers shows the same trend as reported in the study of Warren et al. [19], however to a weaker degree.

3.5. Promoter Methylation Analysis. During reprogramming, DNA is gradually demethylated in critical pluripotency genes (e.g., nanog, oct4) and methylated in genes that are specifically expressed in differentiated cells. As hallmarks of these events, the promoter regions of established pluripotency genes were analyzed. Using bisulfite genomic sequencing, we have shown certain shifts in methylation patterns of Oct4, Nanog and Rex-1 in some genes. While methylation patterns changed, no complete demethylation in these regions after reprogramming was observed (Figure S5B; totally methylated regions: Nanog: 17 versus 19; Oct4: 52 versus 51; Rex1 81 versus 47$)$.

3.6. Teratoma. The injection of hESCs into immunocompromised mice (NOD/LtSz-SCID/SCID) is a standard assay for pluripotency. After injecting $1 \times 10^{6}$ foreskin (factors: OSK), adult fibroblasts (factors: OSTKNM) or Huntington adult fibroblast-(factors: ONSTKM, Figure 5) derived mRNA-iPS cells into NOD/LtSz-SCID/SCID mice, the recipient mice 
Injected: mRNA-iPS cells (derived from Huntington fibroblasts)

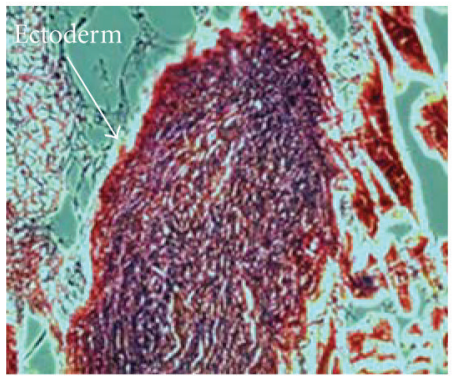

(a)

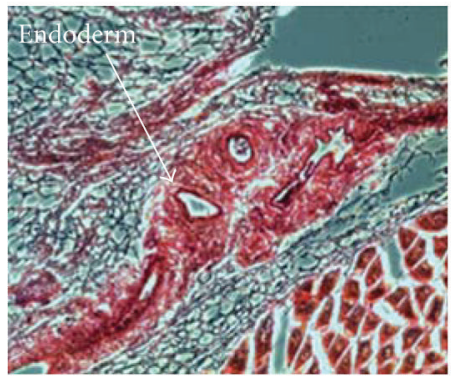

(b)

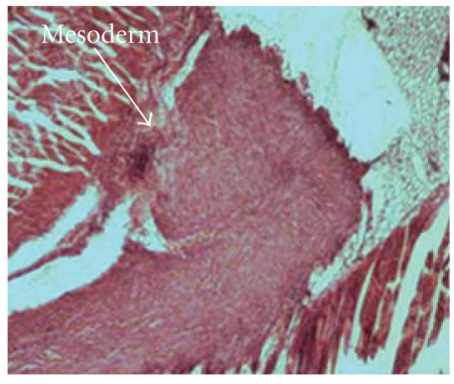

(c)

Injected: viral-derived iPS cells (derived from adult fibroblasts)

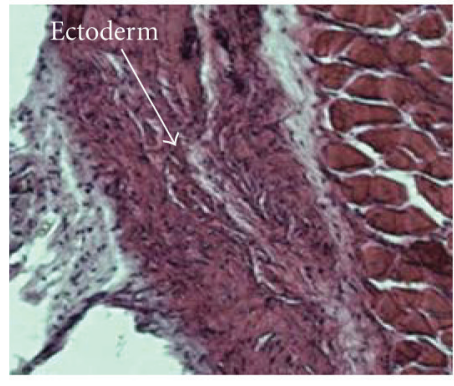

(d)

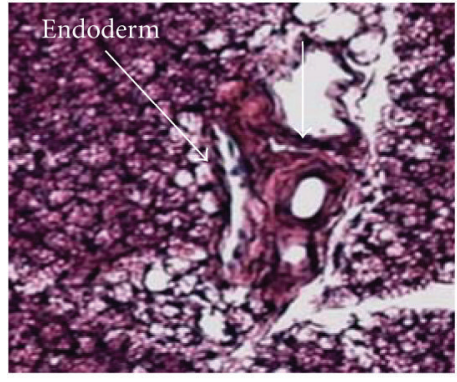

(e)

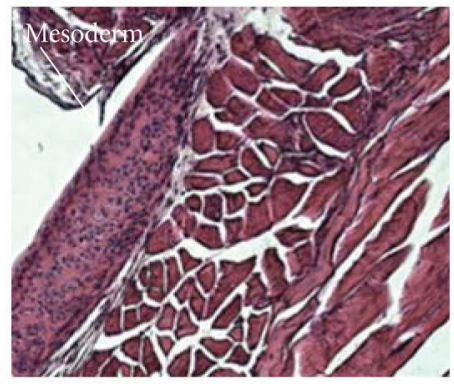

(f)

FIgURE 5: Teratoma assay. NOD/LtSz-SCID/SCID mice were intramuscularly injected with $1 \times 10^{6}$ adult fibroblast-(factors: ONSTKM, Huntington donor, 56 years) derived mRNA-iPS cells and viral iPS cells together with Matrigel. After 8 weeks, the injected regions were dissected and stained with hematoxylin/eosin. Teratoma formations are detected in all analyzed tissues.

showed teratoma formation after 2 months. NOD/SCID mice were also injected with mRNA-transfected cells without visible colonies (Figure 5) and virus-derived iPS colonies. Differentiation into all 3 germ layers could be observed.

3.7. Karyotype Analysis. Extensive manipulation of cells can cause karyotypic changes. To determine possible chromosomal aberrations, we performed chromosome banding analysis. Cytogenetic analysis of all donor fibroblasts and iPS cells showed normal karyotypes (Figure S1C). The viral iPS cells also showed normal karyotypes (Figure S3C).

\section{Discussion}

In most instances, mRNA supplementation only transiently modifies cell behavior. The mRNA provided is transcribed and degraded. The highest expression in GFP-transfected cells was described for 48 hours after transfection and did not persist in the cells for more than 6 days [37]. In the current setup, this prompts the need for repetitive transfections with mRNA over 2 weeks until a threshold is reached where endogenous pluripotency genes are activated.

After transcription of endogenous pluripotency genes (i.e., oct 4 , sox 2 , nanog), the autologous regulatory pathways of these transcription factors are activated and mRNA transfection is no longer necessary after 2 weeks. Our results show that interferon-directed blocking is not necessary to generate iPS colonies using mRNA transfection. As compared to data reported by Warren et al. [19], less iPS colonies were generated in our experiments, however. Colony efficiency was around $0.0005 \%$ with the factor combinations OSK and ONT, while Warren et al. [19] showed 1.4\% efficiency with the OSKN factor combination. We think that a combination of transfections using both electroporation and lipofection is helpful during reprogramming. Furthermore, the optimization of the resting periods between the repeated transfection rounds could support the establishment of iPS colonies without interferon blocking.

All mRNA-iPS cells showed hESC-typical pluripotency markers, morphology, and differentiation into all three germ layers.

mRNA-iPS cells largely lost their fibroblast-characteristic gene expression and acquired mainly hESC characteristics, including the up-regulation of the common pluripotency genes Oct4, Sox2, Klf4, c-Myc, and Nanog. The fact that we found a very similar set of genes that is differentially expressed in mRNA-iPS cells derived from either foreskin or adult fibroblast suggests a stable reprogramming process using mRNA.

However, when large gene lists are taken into account, similarities between mRNA-iPS cells and hESCs begin to dilute. This is illustrated in the ICA analysis (Figures 5(b) and $5(d)$ ). These analyses reveal potential dissimilarities between different hESC lines and even within two samples from the same line. This great heterogeneity of hESC profiles is well known (Stem Cells Initiative; [38]) and seems to be mirrored 


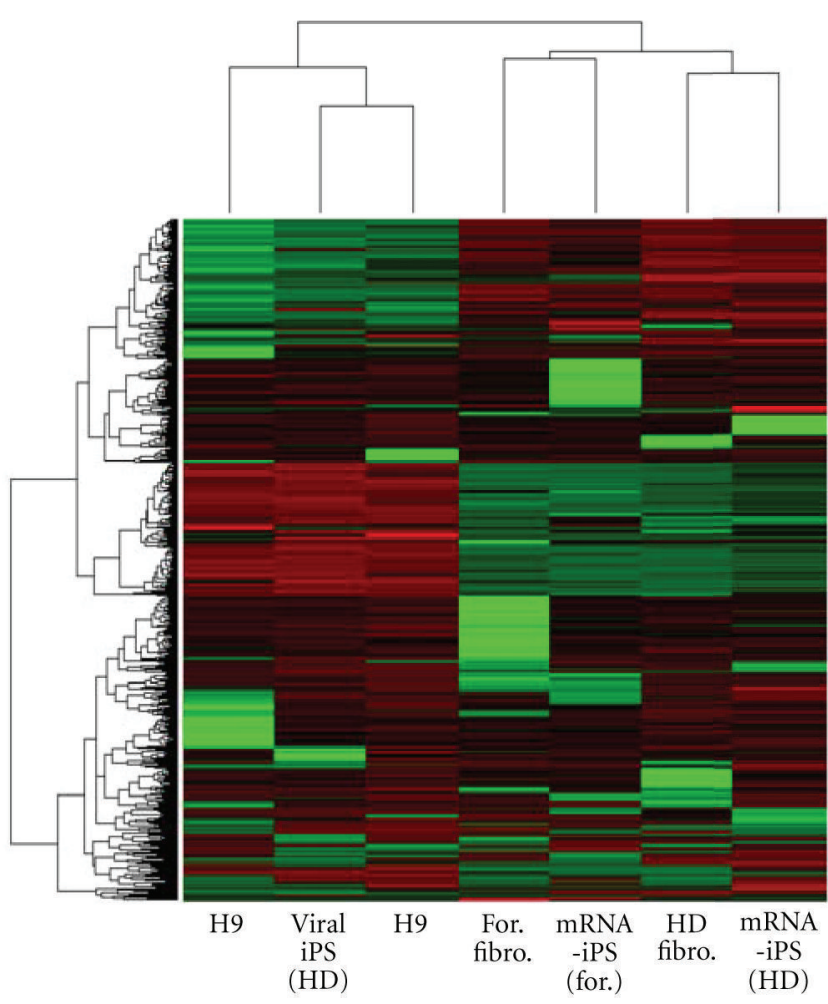

(a) Expression analysis: hierarchical clustering

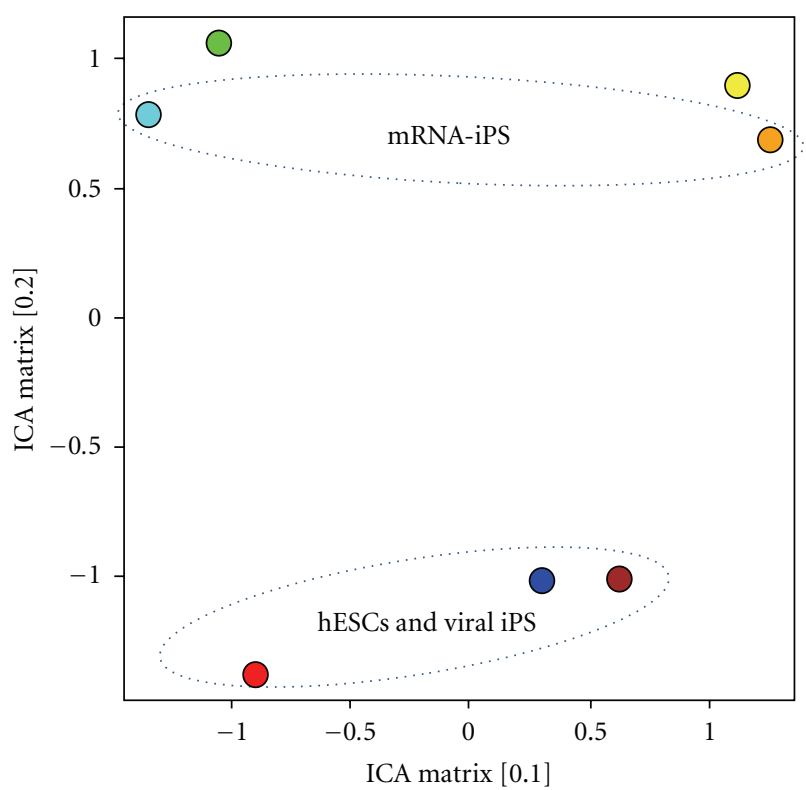

$\begin{array}{ll}\text { H9 (hESCs) } & \bigcirc \text { HD fibro. } \\ \text { H9 (hESCs) } & \bigcirc \text { mRNA-iPS (HD) } \\ \text { For. fibo. } & \bigcirc \text { Viral iPS (HD) } \\ \text { mRNA-iPS (for.) } & \end{array}$

(b) ICA analysis

FIGURE 6: Microarray expression analysis. Hierarchical clustering heat map (a) and ICA plot (b) of genes obtained from two-class comparisons of adult fibroblasts-versus-adult iPS ( 571 genes) and ESC-versus-adult iPS (2084 genes). The data reveal predominant similarity among the ESCs on the one hand and between the fibroblasts and the derived iPS on the other hand. Cell samples were H9 (= hESCs), viPS (adult skin Huntington disease retrovirus-derived iPS cells), fFib (foreskin fibroblasts), fiPS (foreskin mRNA-derived iPS cells), aFib (adult skin Huntington disease fibroblasts), and aiPS (adult skin Huntington disease mRNA-derived iPS cells).

in iPS cells [39]. This presents a theoretical problem in delineating the borders of acceptable similarity between ESCs and iPS cells under more in-depth analysis.

To compare the mRNA method with the conventional viral approach for producing iPS cell lines, we produced iPS cells through viral transduction according to the Yamanaka protocol [2] with the addition of hTERT, as suggested by Mali et al. [40], and Nanog, as described by Yu et al. [3]. These retroviral vector-derived iPS cells show similar characteristics, morphology, and differentiation capacity as mRNAiPS cells, but again, the gene array revealed some differences between viral iPS and the mRNA-iPS cells. Teratomas contain derivatives of all three embryonic germ layers as a proof of the in vivo pluripotency of cells. Teratoma formations could be observed using mRNA-iPS and viral iPS cells, showing that these cells might be pluripotent in vivo. It is worthwhile to mention that not all cells with pluripotency markers created according to the Yamanaka virus protocol form teratomas [39].

With about 30 days from the first transfection until colony formations, reprogramming using mRNA requires slightly more time than the 25 days described for virus-mediated reprogramming [2] but works faster than the 56 days reported for the protein transfection method [16]. However, we found a relatively low colony frequency of about $0.0005 \%$ of input cells compared to $0.001 \%$ for protein-derived iPS cells [16] and $0.01 \%$ for retrovirus-derived iPS cells [2].

Substantial differences in reprogramming efficiency were neither observed between foreskin fibroblasts and adult skin fibroblasts, nor between healthy and Huntington donors, nor between different factor combinations. The only minor difference was revealed with respect to the number of initial colonies.

It is known that the stoichiometry of reprogramming factor expression is a critical contributing factor to successful iPS cell generation [41]. We believe that the technique presented here can be used to vary the timing and dosing of reprogramming impulses.

Hypoxia seemed to have no effect on the efficiency of reprogramming, but promotes the stability of pluripotency in mRNA-iPS cells. It is known that low-oxygen culturing (5\%) upregulates hypoxia-inducing factors (HIF) in hESCs. HIF in turn upregulates transcription factors including Sox2, Oct4, and Nanog [42].

One of the most important aspects of the technology for reprogramming somatic cells to a pluripotent state is the ability to generate disease-specific iPS cell lines. Diseasespecific iPS cells could serve as a new material for pathophysiology, disease modeling, and toxicology studies since established animal models cannot mimic all complex aspects 


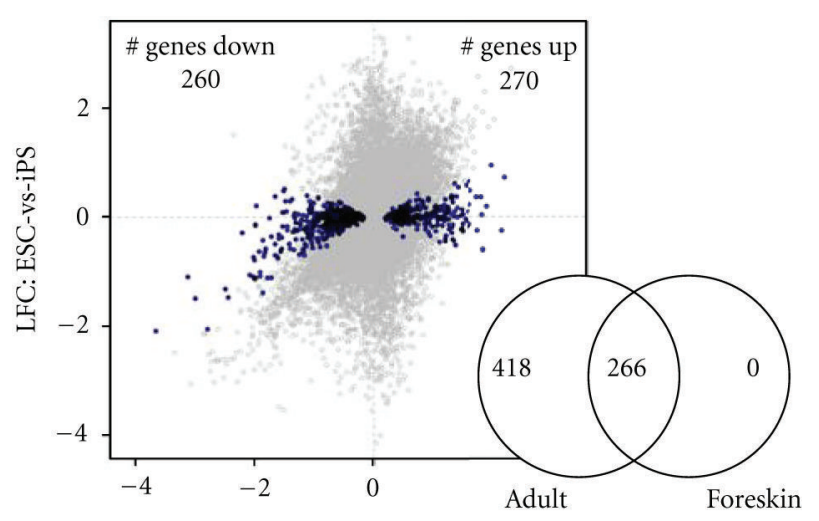

(a) Genes similar in hESC and adult Huntington mRNA-iPS

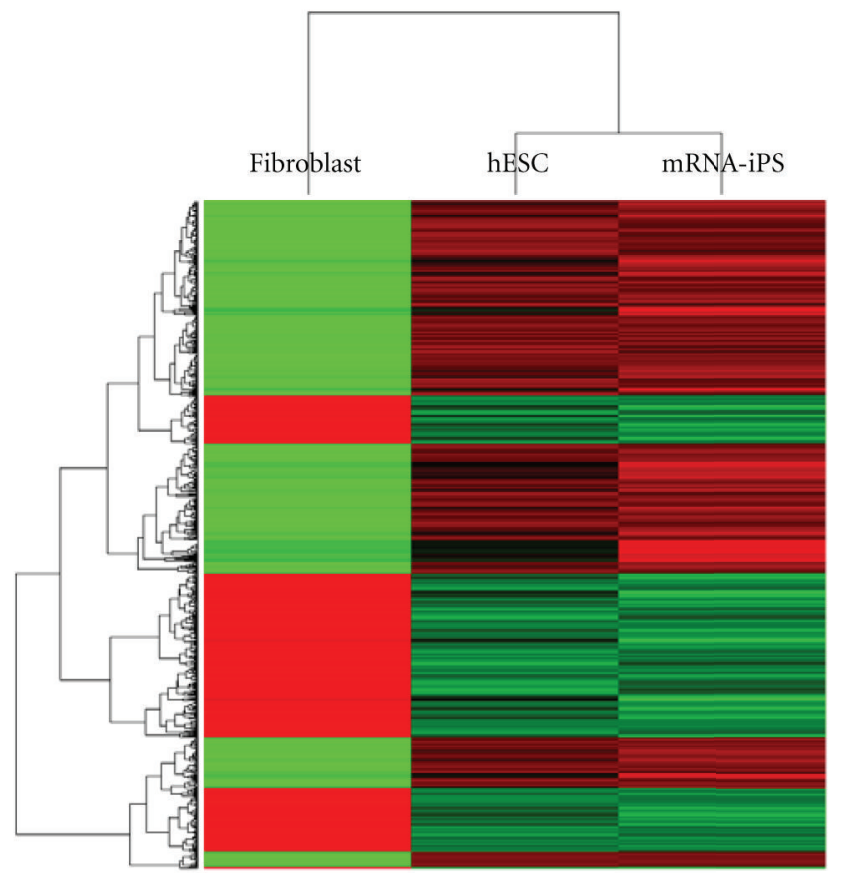

(c) Heatmap of set (a)

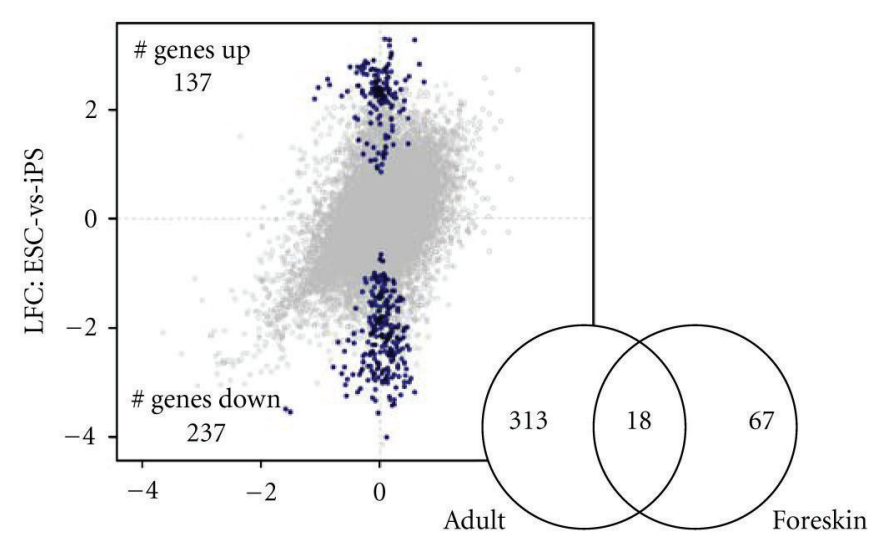

(b) Genes different in hESC and adult Huntington mRNA-iPS

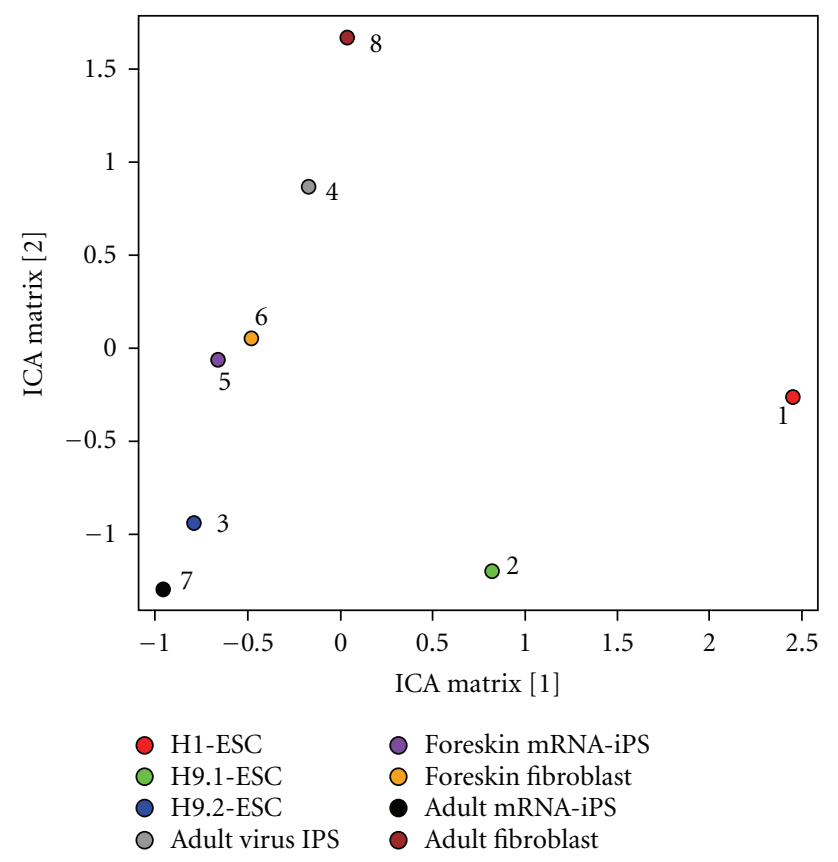

(d) ICA—plot of set (a)

FIgURE 7: Microarray expression analysis. Three-class comparison between fibroblasts and mRNA-iPS cells (factors ONSTKM) from the same donor (adult male, 56, Huntington patient) and hESCs (H9). Logged fold changes (LFC) of genes differentially expressed between mRNA-iPS cells and their donor fibroblasts but similarly expressed in mRNA-iPS cells and hESCs (a) and the corresponding orthogonal selection of genes (b). Grey dots refer to genes with expression changes below the significance level. The hierarchical clustering heat map and the ICA plot of the genes selected in part (a) are shown in parts (c) and (d), respectively. The insertions in parts (a) and (b) show Venn diagrams to illustrate the overlap with the respective genes lists obtained from a three-class comparison of foreskin cells.

and symptoms of human disease (e.g., neurodegenerative disease [43-45]). Here, we present the generation of Huntington-specific iPS cell lines through a nonintegrating reprogramming method. Huntington disease causes progressive degeneration of neurons in cerebral cortex and striatum. The reasons for this degeneration are yet unknown. The differentiation of Huntington mRNA-iPS cells into functional neurons and the study of their behavior and survival conditions may lead to a better understanding of the disease mechanisms and hopefully to the discovery of potential pharmaceutical treatments. In summary, we present an alternative method for mRNA-induced reprogramming of adult human fibroblasts to an induced pluripotent state. Further studies are required to compare in greater detail mRNA-iPS cells to cells created with viral and protein transfection methods and to improve the efficiency of the method.

\section{Acknowledgments}

Thanks are due to Dr. S. Sethe for assistance with data interpretation and manuscript preparation. Special thanks are also due to Dr. T. Piroth for providing the Huntington fibroblasts. The authors thank the IZKF of the University of 
Leipzig for performing gene array measurements and virology, especially Professor Liebert and Dr. Brinkmann for providing help with viral iPS derivation. Dr. Federova and Dr. Holland helped with the karyotype analysis. Dr. Jeremy Brown helped with the methylation analysis. Henry Wirth was kindly supported by the Helmholtz Impulse and Networking Fund through the Helmholtz Interdisciplinary Graduate School for Environmental Research (HIGRADE). The project was supported by the Fraunhofer Foundation project "Tissue engineering on demand". Guido Nikkhah was kindly supported by the German Parkinson Foundation.

\section{References}

[1] K. Takahashi and S. Yamanaka, "Induction of pluripotent stem cells from mouse embryonic and adult fibroblast cultures by defined factors," Cell, vol. 126, no. 4, pp. 663-676, 2006.

[2] K. Takahashi, K. Tanabe, M. Ohnuki et al., "Induction of pluripotent stem cells from adult human fibroblasts by defined factors," Cell, vol. 131, no. 5, pp. 861-872, 2007.

[3] J. Yu, M. A. Vodyanik, K. Smuga-Otto et al., "Induced pluripotent stem cell lines derived from human somatic cells," Science, vol. 318, no. 5858, pp. 1917-1920, 2007.

[4] W. E. Lowry, L. Richter, R. Yachechko et al., "Generation of human induced pluripotent stem cells from dermal fibroblasts," Proceedings of the National Academy of Sciences of the United States of America, vol. 105, no. 8, pp. 2883-2888, 2008.

[5] J. T. Dimos, K. T. Rodolfa, K. K. Niakan et al., "Induced pluripotent stem cells generated from patients with ALS can be differentiated into motor neurons," Science, vol. 321, no. 5893, pp. 1218-1221, 2008.

[6] I. H. Park, N. Arora, H. Huo et al., "Disease-specific induced pluripotent stem cells," Cell, vol. 134, no. 5, pp. 877-886, 2008.

[7] A. D. Ebert, J. Yu, F. F. Rose et al., "Induced pluripotent stem cells from a spinal muscular atrophy patient," Nature, vol. 457, no. 7227, pp. 277-280, 2009.

[8] E. Kiskinis and K. Eggan, "Progress toward the clinical application of patient-specific pluripotent stem cells," Journal of Clinical Investigation, vol. 120, no. 1, pp. 51-59, 2010.

[9] C. Freund and C. L. Mummery, "Prospects for pluripotent stem cell-derived cardiomyocytes in cardiac cell therapy and as disease models," Journal of Cellular Biochemistry, vol. 107, no. 4, pp. 592-599, 2009.

[10] M. Stadtfeld, M. Nagaya, J. Utikal, G. Weir, and K. Hochedlinger, "Induced pluripotent stem cells generated without viral integration," Science, vol. 322, no. 5903, pp. 945-949, 2008.

[11] K. Okita, M. Nakagawa, H. Hyenjong, T. Ichisaka, and S. Yamanaka, "Generation of mouse induced pluripotent stem cells without viral vectors," Science, vol. 322, no. 5903, pp. 949953, 2008.

[12] F. Soldner, D. Hockemeyer, C. Beard et al., "Parkinson's disease patient-derived induced pluripotent stem cells free of viral reprogramming factors," Cell, vol. 136, no. 5, pp. 964-977, 2009.

[13] K. Kaji, K. Norrby, A. Paca, M. Mileikovsky, P. Mohseni, and K. Woltjen, "Virus-free induction of pluripotency and subsequent excision of reprogramming factors," Nature, vol. 458, no. 7239, pp. 771-775, 2009.

[14] K. Woltjen, I. P. Michael, P. Mohseni et al., "PiggyBac transposition reprograms fibroblasts to induced pluripotent stem cells," Nature, vol. 458, no. 7239, pp. 766-770, 2009.
[15] D. Huangfu, K. Osafune, R. Maehr et al., "Induction of pluripotent stem cells from primary human fibroblasts with only Oct4 and Sox2," Nature Biotechnology, vol. 26, no. 11, pp. 1269-1275, 2008.

[16] D. Kim, C. H. Kim, J. I. Moon et al., "Generation of human induced pluripotent stem cells by direct delivery of reprogramming proteins," Cell Stem Cell, vol. 4, no. 6, pp. 472-476, 2009.

[17] H. Zhou, S. Wu, J. Y. Joo et al., "Generation of induced pluripotent stem cells using recombinant proteins," Cell Stem Cell, vol. 4, no. 5, pp. 381-384, 2009.

[18] J. M. Wiehe, P. Ponsaerts, M. T. Rojewski et al., "mRNA-mediated gene delivery into human progenitor cells promotes highly efficient protein expression," Journal of Cellular and Molecular Medicine, vol. 11, no. 3, pp. 521-530, 2007.

[19] L. Warren, P. D. Manos, T. Ahfeldt et al., "Highly efficient reprogramming to pluripotency and directed differentiation of human cells with synthetic modified mRNA," Cell Stem Cell, vol. 7, no. 5, pp. 618-630, 2010.

[20] M. Angel and M. F. Yanik, "Innate immune suppression enables frequent transfection with RNA encoding reprogramming proteins," PLoS ONE, vol. 5, no. 7, Article ID e11756, 2010.

[21] E. Yakubov, G. Rechavi, S. Rozenblatt, and D. Givol, "Reprogramming of human fibroblasts to pluripotent stem cells using mRNA of four transcription factors," Biochemical and Biophysical Research Communications, vol. 394, no. 1, pp. 189-193, 2010.

[22] J. A. Thomson, "Embryonic stem cell lines derived from human blastocysts," Science, vol. 282, no. 5391, pp. 1145-1147, 1998.

[23] C. T. Freberg, J. A. Dahl, S. Timoskainen, and P. Collas, "Epigenetic reprogramming of OCT4 and NANOG regulatory regions by embryonal carcinoma cell extract," Molecular Biology of the Cell, vol. 18, no. 5, pp. 1543-1553, 2007.

[24] T. Schnell, P. Foley, M. Wirth, J. Münch, and K. Überla, “Development of a self-inactivating, minimal lentivirus vector based on simian immunodeficiency virus," Human Gene Therapy, vol. 11, no. 3, pp. 439-447, 2000.

[25] J. K. Yee, T. Friedmann, and J. C. Burns, "Generation of high-titer pseudotyped retroviral vectors with very broad host range," Methods in Cell Biology, vol. 43, part A, pp. 99-112, 1994.

[26] S. Schuck, A. Manninen, M. Honsho, J. Füllekrug, and K. Simons, "Generation of single and double knockdowns in polarized epithelial cells by retrovirus-mediated RNA interference," Proceedings of the National Academy of Sciences of the United States of America, vol. 101, no. 14, pp. 4912-4917, 2004.

[27] C. M. Counter, W. C. Hahn, W. Wei et al., "Dissociation among in vitro telomerase activity, telomere maintenance, and cellular immortalization," Proceedings of the National Academy of Sciences of the United States of America, vol. 95, no. 25, pp. 14723-14728, 1998.

[28] C. Dai, L. Whitesell, A. B. Rogers, and S. Lindquist, "Heat shock factor 1 is a powerful multifaceted modifier of carcinogenesis," Cell, vol. 130, no. 6, pp. 1005-1018, 2007.

[29] H. Binder and S. Preibisch, "'Hook'-calibration of GeneChipmicroarrays: theory and algorithm," Algorithms for Molecular Biology, vol. 3, no. 1, article 12, 2008.

[30] B. M. Bolstad, R. A. Irizarry, M. Åstrand, and T. P. Speed, "A comparison of normalization methods for high density oligonucleotide array data based on variance and bias," Bioinformatics, vol. 19, no. 2, pp. 185-193, 2003. 
[31] K. Kadota, Y. Nakai, and K. Shimizu, "A weighted average difference method for detecting differentially expressed genes from microarray data," Algorithms for Molecular Biology, vol. 3, no. 1, article 8, 2008.

[32] N. Jain, J. Thatte, T. Braciale, K. Ley, M. O'Connell, and J. K. Lee, "Local-pooled-error test for identifying differentially expressed genes with a small number of replicated microarrays," Bioinformatics, vol. 19, no. 15, pp. 1945-1951, 2003.

[33] Y. Xie, W. Pan, and A. B. Khodursky, "A note on using permutation-based false discovery rate estimates to compare different analysis methods for microarray data," Bioinformatics, vol. 21, no. 23, pp. 4280-4288, 2005.

[34] L. Tian, S. A. Greenberg, S. W. Kong, J. Altschuler, I. S. Kohane, and P. J. Park, "Discovering statistically significant pathways in expression profiling studies," Proceedings of the National Academy of Sciences of the United States of America, vol. 102, no. 38, pp. 13544-13549, 2005.

[35] B. Bhattacharya, T. Miura, R. Brandenberger et al., "Gene expression in human embryonic stem cell lines: unique molecular signature,” Blood, vol. 103, no. 8, pp. 2956-2964, 2004.

[36] B. Efron and R. Tibshirani, "On testing the significance of sets of genes," Annals of Applied Statistics, vol. 1, pp. 107-129, 2007.

[37] V. F. I. Van Tendeloo, P. Ponsaerts, F. Lardon et al., "Highly efficient gene delivery by mRNA electroporation in human hematopoietic cells: superiority to lipofection and passive pulsing of mRNA and to electroporation of plasmid cDNA for tumor antigen loading of dendritic cells," Blood, vol. 98, no. 1, pp. 49-56, 2001.

[38] O. Adewumi, B. Aflatoonian, L. Ahrlund-Richter et al., "Characterization of human embryonic stem cell lines by the International Stem Cell Initiative," Nature Biotechnology, vol. 25, no. 7, pp. 803-816, 2007.

[39] E. M. Chan, S. Ratanasirintrawoot, I. H. Park et al., "Live cell imaging distinguishes bona fide human iPS cells from partially reprogrammed cells," Nature Biotechnology, vol. 27, no. 11, pp. 1033-1037, 2009.

[40] P. Mali, Z. Ye, H. H. Hommond et al., "Improved efficiency and pace of generating induced pluripotent stem cells from human adult and fetal fibroblasts," Stem Cells, vol. 26, no. 8, pp. 1998-2005, 2008.

[41] E. P. Papapetrou, M. J. Tomishima, S. M. Chambers et al., "Stoichiometric and temporal requirements of Oct4, Sox2, $K l f 4$, and $c-M y c$ expression for efficient human iPSC induction and differentiation," Proceedings of the National Academy of Sciences of the United States of America, vol. 106, no. 31, pp. 12759-12764, 2009.

[42] C. E. Forristal, K. L. Wright, N. A. Hanley, R. O. C. Oreffo, and F. D. Houghton, "Hypoxia inducible factors regulate pluripotency and proliferation in human embryonic stem cells cultured at reduced oxygen tensions," Reproduction, vol. 139, no. 1, pp. 85-97, 2010.

[43] S. M. Fleming, P.-O. Fernagut, and M.-F. Chesselet, "Genetic mouse models of Parkinsonism: strengths and limitations," NeuroRx, vol. 2, no. 3, pp. 495-503, 2005.

[44] M. Newman, F. I. Musgrave, and M. Lardelli, "Alzheimer disease: amyloidogenesis, the presenilins and animal models," Biochimica et Biophysica Acta, vol. 1772, no. 3, pp. 285-297, 2007.

[45] J. A. Potashkin, S. R. Blume, and N. K. Runkle, "Limitations of animal models of Parkinson's disease," Parkinson's Disease, vol. 2011, Article ID 658083, 7 pages, 2011. 

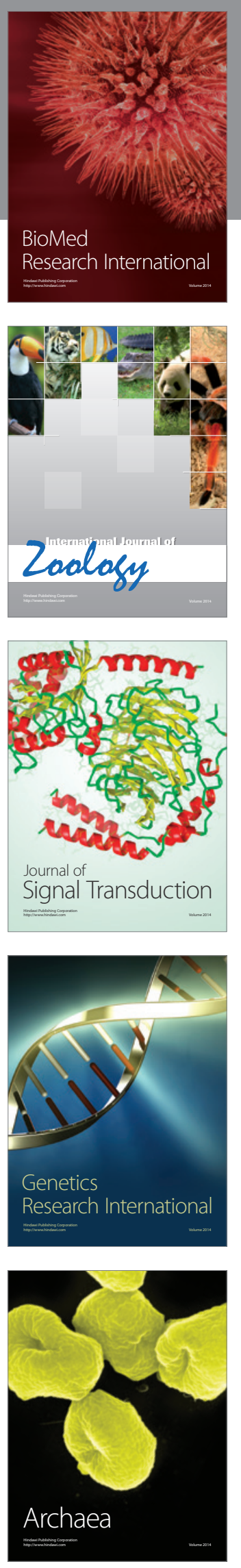
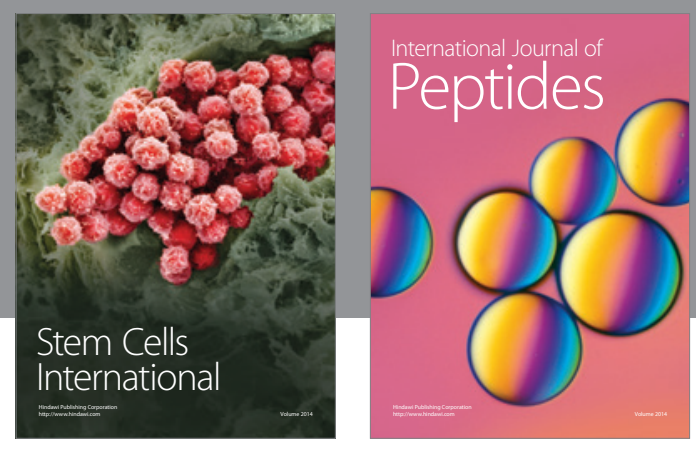

Submit your manuscripts at

http://www.hindawi.com
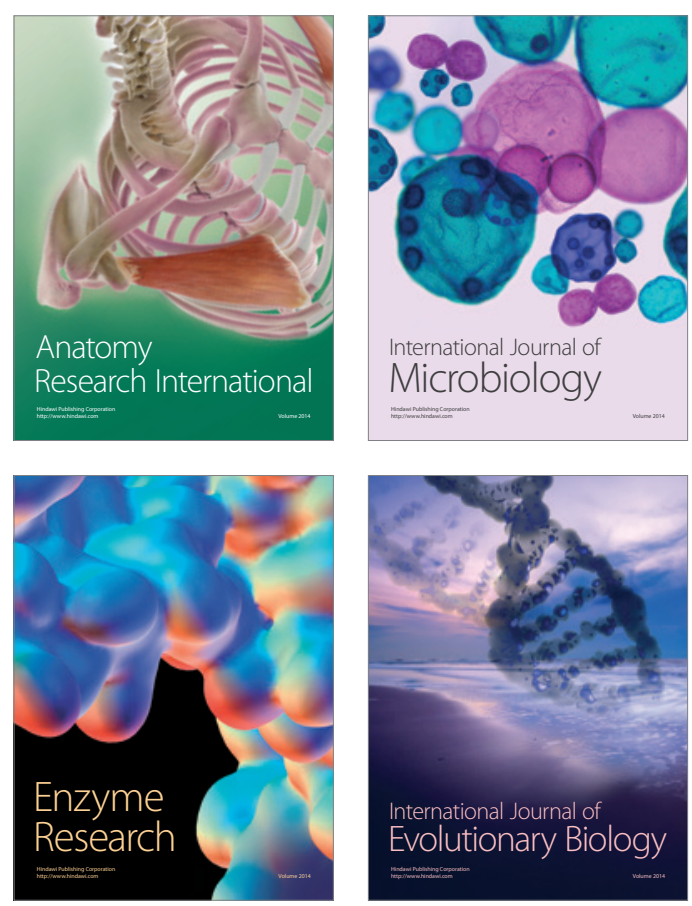
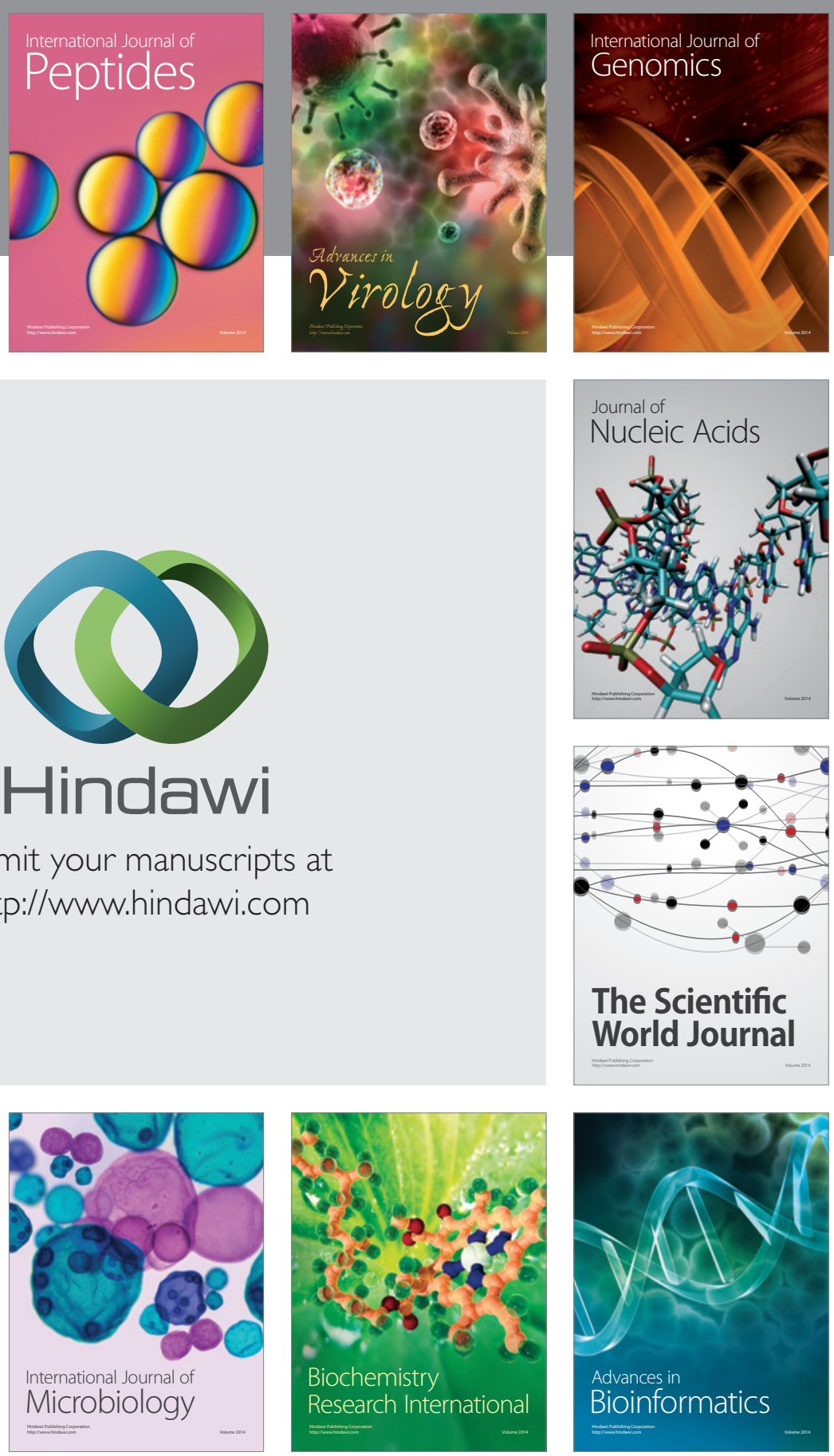

The Scientific World Journal
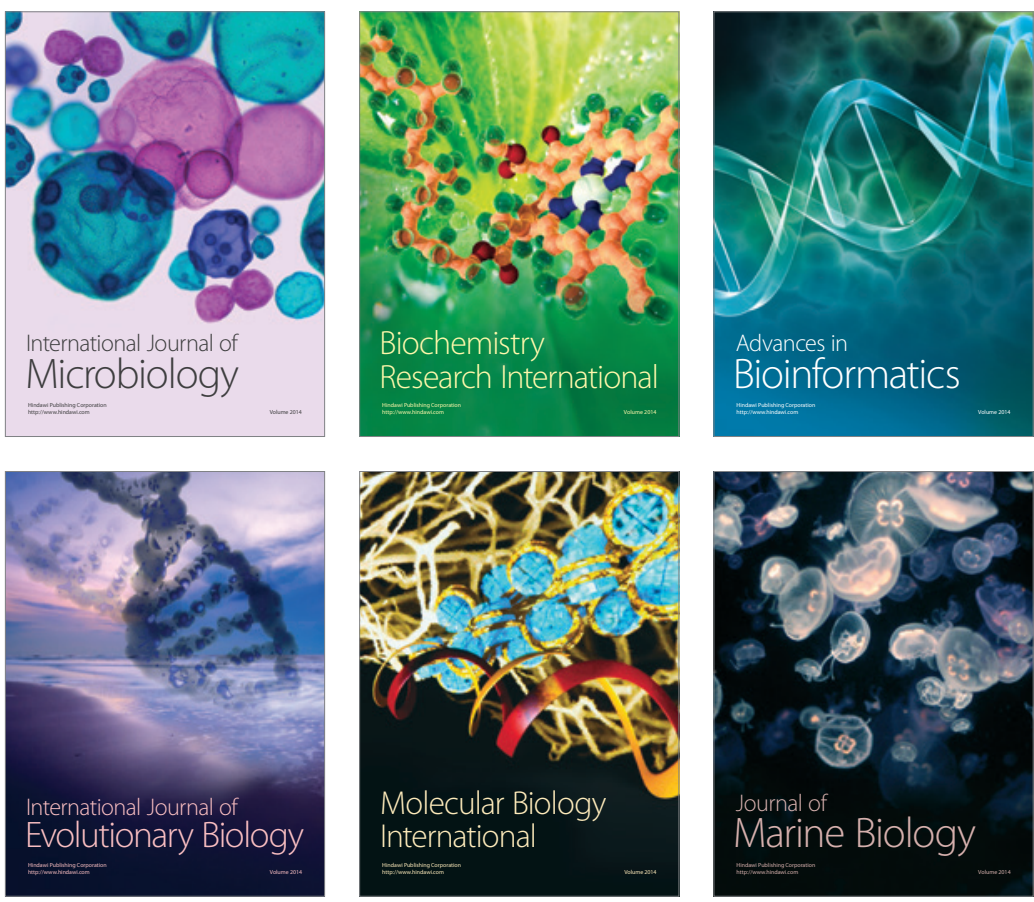